
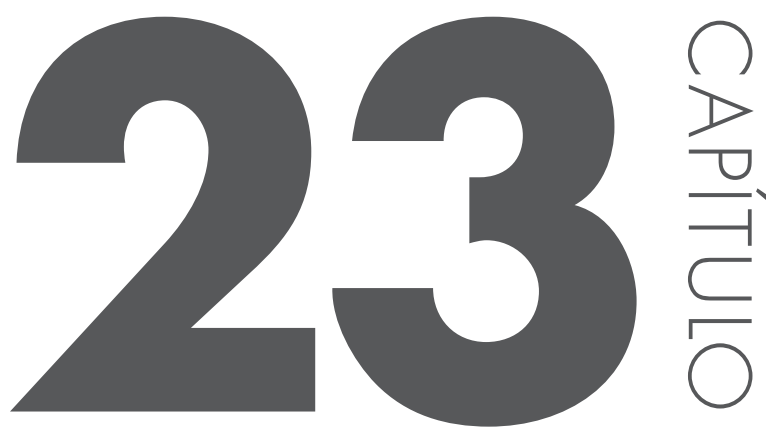

\title{
LUTA PELA PERMANÊNCIA NA TERRA: as estratégias de reprodução camponesa na Comunidade Ribeirão em Catalão (GO)
}

Nascimento Rosa, Marcelo do ${ }^{1 *}$; Stacciarini, José Henrique Rodrigues 2 1 Mestrando no Programa de Pós-Graduação em Geografia da Universidade Federal de Goiás/Regional Catalão. Membro do Núcleo de Pesquisa Geografia, Trabalho e Movimentos Sociais - GETeM/CNPq. Bolsista CAPES/CNPq

2 Professor Doutor do Programa de Pós-Graduação em Geografia da Universidade Federal de Goiás, Regional/Catalão

*e-mail: marcelo.geoufg@gmail.com

\section{RESUMO}

Esse artigo refere-se a uma reflexão acerca da temática pesquisada no projeto de pesquisa desenvolvido junto ao Programa de Pós Graduação em Geografia/UFG/Regional Catalão e resulta de estudos e reflexões realizados no Grupo de Pesquisa Geografia, Trabalho e Movimentos Sociais da Universidade Federal de Goiás - Regional Catalão, bem como da militância no Movimento Camponês Popular (MCP). Nesse sentido, parte-se do diário de campo, da vivência junto às famílias camponesas e de reflexões teóricas para compreender as estratégias que os camponeses desenvolvem para permanecer na terra de trabalho, a partir da tríade terra-trabalho- 
família. Assim a compreensão das estratégias adotadas pelos camponeses a fim de garantir a sua permanência na terra de trabalho requer a discussão de conceitos que expliquem a evidência histórica e o caráter diferencial e contraditório que a autonomia camponesa representa no modo capitalista de produção tendo a Comunidade Ribeirão no município de Catalão/Goiás como recorte espacial de análise.

Palavras-chave: Camponeses; Estratégias; Permanência na Terra Pesquisa, Pós-Graduação e Inovação da Regional Catalão (2. : 2014 : Goiás) Coletânea Interdisciplinar em Pesquisa, Pós- Graduação e Inovação - Volume 1 : Estudos Ambientais, Território e Movimentos Sociais. Anais [livro eletrônico] / organizado por Adriana Freitas Neves, Idelvone Mendes Ferreira, Maria Helena de Paula, Petrus Henrique Ribeiro dos Anjos. São Paulo: Blucher, 2015. ISBN: 978-85-8039-109-1, DOI 10.5151/9788580391091-V1_Cap23 


\section{CAMPESINATO: REFLEXÕES TEÓRICAS}

O capitalismo comporta relações capitalistas e não capitalistas, já existentes antes ou não em decorrência do seu processo de desenvolvimento desigual e contraditório. Assim, o campesinato resiste em meio ao capitalismo, contrariando os prognósticos sobre o seu desaparecimento. Dessa maneira, o conceito de campesinato é fator de máxima importância e será estudado teórica e empiricamente. Vários autores como, Alexandrina Conceição Luz, Alexander Chayanov, Ariovaldo Umbelino de Oliveira, Eliane Tomiasi Paulino, Horácio Martins Carvalho, José de Souza Martins, Marcelo Rodrigues Mendonça, Ricardo Abramovay entre outros, já estudaram a existência dos camponeses no capitalismo e alicerçarão a compreensão das estratégias para a permanência na terra de trabalho.

A territorialização do capital, e a consequente expansão das relações capitalistas no campo não acabam completamente com outros tipos de relação de produção e trabalho dos sujeitos nesse espaço. Formas diferentes de (re) produção passam a ocorrer no interior do sistema capitalista. Sendo assim, o conceito de território, compreendido a partir das relações de poder, proporciona o entendimento da singularidade na totalidade para além do observado na base física.

A expressão luta pela permanência na terra implica no fato de que o camponês já está territorializado, mas precisa garantir condições para viver nela e dela com dignidade, sabendo que não está isolado da realidade e nem poderia estar. Essa luta é uma reação à não aceitação da expropriação como condição predestinada. É uma busca, nas contradições do modo capitalista de produção, de estratégias para continuar se reproduzindo.

Entre estas estratégias pode se observar a divisão de tarefas entre os membros da família camponesa e a ação política nos movimentos sociais. Os camponeses, assim, asseguram a renda da terra e do trabalho, bem como o modo de produzir e viver. A luta, mesmo que relativa, pela autonomia perante as relações capitalistas, constrói diversas territorialidades potenciais e alternativas ao agronegócio que ainda não foram considerados adequadamente pela academia.

Assim, a compreensão das estratégias adotadas pelos camponeses a fim de garantir a sua permanência na terra de trabalho requer a discussão de conceitos que expliquem a evidência histórica e o caráter diferencial e contraditório que a autonomia camponesa representa no modo capitalista de produção. 


\section{OS CAMPONESES}

Com a territorialização do mercantilismo europeu no Brasil, deixaram de existir as diferentes formas de organização comunal que havia. A contaminação capitalista de todas as relações fez com que índios e negros, grupos aprisionados, coagidos e, por isso mesmo, dissidente, em luta pela liberdade e por terras para sua sobrevivência estabelecessem uma união entre si e com os europeus e seus descendentes banidos do pacto de acumulação instalado no país, dando origem, assim, ao campesinato brasileiro e sua incansável luta pela terra de trabalho em resposta ao histórico processo de expulsão e migrações imposto pelo avanço do capital. É a posse da terra, mesmo que precária, que afasta o assalariamento e permite a reafirmação da autonomia do trabalho.

No Brasil, embora o campesinato tenha sido atingido negativamente por um lado, pela Lei de Terras de 1850, por outro, como retrata Oliveira (2002), a transformação da posse em propriedade, ajudou a consolidar parte do campesinato no Brasil. Durante todo o período em que vigorou o critério de posse, o campesinato se constituiu numa classe precária, em migração permanente em decorrência das concessões de títulos de sesmarias (século XVI) à população branca, aos fidalgos e demais escolhidos pela Coroa portuguesa e depois pelo Império brasileiro. Assim, como afirma Martins (1995), os camponeses estavam ausentes da composição de forças produtivas reconhecidas como tal.

Contraditoriamente, é a transformação da terra em mercadoria que permite a inserção do campesinato como classe no cenário das representações políticas. $\mathrm{O}$ camponês deixa de ser sobrante e passa a integrar o sistema pelo simples fato de se tornar proprietário, independentemente do tamanho da terra, numa sociedade em que o critério de inclusão é a propriedade privada. Enfim, é o reconhecimento jurídico-institucional do pequeno agricultor autônomo que vai consolidar, no pacto político, a existência camponesa.

Outro ponto de discussão e de discordância em relação aos camponeses são as concepções de que os camponeses são seres sociais isolados, ausentes de relações de mercado por se dedicarem à autossuficiência de forma rústica. Essa concepção tem origem em Kautsky (1980), que compartilhava de parte das ideias de Lenin e Marx. Apesar de se reconhecer a importância do pensamento de tais teóricos, é necessário indagar a integral transposição de suas análises para a realidade de hoje, uma vez que seus estudos analisaram um universo muito particular e um tempo histórico que acabara de sofrer profundas transformações urbanoindustriais. Todavia, muitos pesquisadores da questão agrária tomaram os estudos de Lenin e Kautsky como profecia, desconsiderando que o território é dinâmico e vai adquirindo feições conforme o permanente movimento da realidade. 
Esse posicionamento tem levado vários estudos sobre os camponeses a adotarem uma leitura congelada da realidade brasileira, que conduz a uma abordagem preconceituosa do papel político dos camponeses em nossa sociedade. Isso é tão real que, ao buscarem mediação com setores progressistas - comunistas -, as Ligas Camponesas foram orientadas a partir de concepções clássicas que as levaram a um distanciamento de suas verdadeiras aspirações e a uma "disfarçada" tutela.

É essa incapacidade de compreender o verdadeiro sentido das lutas camponesas que levou e leva à perda da unidade entre os partidos e organizações populares que, na maioria das vezes, significa um refluxo das lutas, como o que aconteceu nas décadas de 1950 e 1960 com as Ligas Camponesas, que culminou no golpe militar de 1964.

Paulino (2006, p. 38) argumenta sobre essa dificuldade de compreensão do ideário camponês, dizendo que:

Entende-se que essa dificuldade provém da não consideração de um elemento essencial que orienta a utopia camponesa, a busca destinada da autonomia, da liberdade de dispor de seu tempo, espaço e saber de acordo com os sonhos e projetos construídos ao longo das próprias tradições.

A autonomia é o que conduz ao progresso material dos camponeses, o que somente a propriedade individual da terra parece lhes assegurar. Oliveira (2002) adverte que é preciso ter cuidado com leituras apressadas, pois não se pode tirar dos camponeses o sonho histórico da produção individual autônoma e que somente sua experimentação será capaz de levar à sua superação.

Sendo assim, por falta de um instrumento teórico eficiente para compreender os camponeses face às novas configurações espaciais, sociais e produtivas instaladas à medida que o próprio modo de produção capitalista evolui, esses sujeitos da terra são transformados em meros trabalhadores familiares, supostamente redefinidos pela a perda e pela transformação em "proletários" parciais, o que implica a perda da dimensão de classe. Essa transformação de camponeses em trabalhadores familiares tem uma grande carga ideológica e objetiva banir os camponeses do pacto político.

Os camponeses são ao mesmo tempo trabalhadores da terra (não todos) donos dos seus meios de produção, mas a dificuldade em lidar com o conceito de classe faz com que o único agente que passou a moldar o capitalismo seja sacramentado como sujeitos da história. Nesse sentido, Shanin (1980) diz que, 
[...] o capitalismo "juvenil" e otimista do século XIX influenciou muito a visão marxista clássica. Era visto como agressivo, construtivo, dominador e supereficaz em sua capacidade de se expandir. Como o dedo de Midas que transforma em ouro tudo o que toca o capitalismo também transforma em capitalismo tudo o que toca. A terra é o limite. À luz do que realmente encontramos hoje, tudo isso parece um grande exagero. É indubitável a capacidade de os centros capitalistas explorarem todos e tudo à sua volta; mas sua capacidade ou sua necessidade (em termos de maximização dos lucros) de transformar tudo ao redor à sua semelhança não o é. Os camponeses são um exemplo. (Shanin, 1980, p. 57).

Um dos principais argumentos de que teria ocorrido o desaparecimento dos camponeses é o fato de eles estarem inseridos no mercado e de que as relações mercantis são inerentes ao modo capitalista de produção. Para Chayanov (1974), a inserção no mercado é uma estratégia de fortalecimento, por permitir aos camponeses se dedicarem com mais afinco aos cultivos mais rentáveis, adquirindo no mercado aquilo que não produzem em suas propriedades ou que lhes roubaria mais tempo.

Abramovay (1990, p.124), porém, também entende que a existência do campesinato é incompatível com a vigência do capitalismo como podemos ver a seguir,

As sociedades camponesas são incompatíveis com o ambiente econômico onde imperam relações claramente mercantis. Tão logo os mecanismos de preços adquiram a função de arbitrar as decisões referentes à produção, de funcionar como princípio alocativo do trabalho social, a reciprocidade e a personalização dos laços sociais perderão inteiramente o lugar, levando consigo o próprio caráter burguês da organização social.

Essa afirmação de Abramovay supõe que, se alteradas as bases técnicas, os camponeses desapareceriam, dando lugar a uma nova categoria profissional (os agricultores familiares), implicitamente integrantes da pequena burguesia. Além do mais, o autor rejeita qualquer tipo de produção de capital sobre bases camponesas e isso, como retrata Oliveira (2002), expõe a dificuldade de se aceitar que a realidade é um processo e está em processo, não é estática, definida, acabada.

Para os camponeses o objetivo do ganho é distinto do da lógica de reprodução ampliada capitalista. Chayanov (1974) mostra, como resultado de seus estudos, 
que, para os camponeses, a obtenção de dinheiro tem o objetivo de melhorar as condições de trabalho e, com isso, diminuir o esforço, garantindo mais bemestar para a família. Sendo assim, o fato de os camponeses estarem inseridos no mercado não os torna menos camponeses, pois eles mantêm a autonomia na produção com o trabalho familiar e o destino de seus esforços é a sua reprodução social.

Além do mais, apesar da vinculação ao mercado, é necessário dar atenção a uma outra característica da produção camponesa: a cultura do excedente. Para os camponeses a seleção dos cultivos que resultarão em excedentes para a venda é definida pela capacidade de consumo interno da família. Assim, caso houver qualquer problema na comercialização, a família pode consumir esses produtos. Quando um camponês escolhe plantar comercialmente, ou seja, de forma que o excedente seria tão grande que a família não conseguiria consumilo, se ele controlar os canais de comercialização, por exemplo, com a venda direta aos consumidores, isso também não descaracteriza sua atividade como não estritamente capitalista.

Dessa forma, os rendimentos da família camponesa são a somatória dos proventos percebidos pela família, seja na forma de produtos colhidos e consumidos por ela mesma, seja na forma de dinheiro obtido com transações desses produtos. Porém, quanto maior for a parte da produção destinada ao consumo, maior a segurança alimentar da família e menor a necessidade de recorrer ao mercado para satisfazer as necessidades básicas. Mesmo quando alguns produtos puderem ser comprados em situação vantajosa, e os camponeses a comprarem, levando em conta a relação custo-benefício, os camponeses não estariam perdendo sua autonomia. Para Chayanov (1974, p.142), a relação do camponês com o mercado não representa risco à sua sobrevivência, embora diminua sua autonomia. Assim

Graças a su contacto con el mercado, la exploracion puede eliminar ahora de su plan organizativo todos los sectores de producion que proporcionan pocos ingresos y em cuales el producto se obtiene con un esfuerzo mayor que el requerido para obtener su equivalente em el mercado mediante otras formas de actividad econômica que producen ingresos mayores. En el plan organizativo solo subsiste lo que proporciona uma alta remuneracion para la fuerza de trabajo o constituye um elemento de producion irreemplazable por razones técnicas.

Outro argumento que corrobora o não desaparecimento dos camponeses é o fato de a agricultura ser um setor estratégico dentro do capitalismo e isso 
exige, pelo menos nos países centrais, como o exemplo dos Estados Unidos levantado por Abramovay (1990), a presença do Estado, que, para assegurar oferta abundante de alimentos, garante renda aos camponeses.

Muitos autores, como o próprio Abramovay (1990), por não acreditarem no poder de pressão dos agricultores, explicam a inserção das políticas públicas na agricultura camponesa como uma válvula de escape para salvaguardar as bases da expansão capitalista, permitindo o consumo de bens duráveis, ou seja, a expansão de mercado para os produtos industrializados. Mas há de se ponderar. Paulino (2006) ensina que essa interpretação traz muitas implicações, inclusive a de que "os camponeses são sujeitos passivos, incapazes de influenciar projetos políticos mais amplos” (PAULINO, 2006, p.54)

Dessa forma, o conceito e a existência do campesinato não são problemas teóricos, mas base de projetos políticos de intervenção na realidade. Sobre a dimensão desse conceito, Shanin escreve:

Um camponês não é uma palavra vazia a refletir os preconceitos do populus, as frivolidades linguísticas dos intelectuais ou ainda, conspirações de adeptos de uma ideologia, embora às vezes isso possa ser verdadeiro. Se revogado, este conceito (ainda?) não pode ser facilmente substituído por algo de natureza semelhante. Ele tem, assim como os conceitos de capitalismo, proletariado e, é claro, modo de produção, potenciais de reificação, isto é, pode ser enganoso, assim como ser usado para enganar, especialmente quando utilizado de maneira ingênua. Tem-se dito corretamente que o preço da utilização de modelos é a eterna vigilância. É verdade também que sem tais construções teóricas não seria absolutamente possível qualquer progresso nas ciências sociais. O camponês é uma mistificação principalmente para aqueles que são propensos a se tornar mistificados [...]. Em última instância, os conceitos devem servir não a uma questão de reconciliação dialética de conceitos, mas à compreensão das relações reais. [...] excetuando sua mistificação e sua utilização ideológica, o conceito de campesinato cumpriu, muitas vezes, todos esses serviços. Esta capacidade ainda não se esgotou (SHANIN, 1980, p. 76-77, grifos do autor).

Assim, ao se eleger as relações econômicas como centro de análise, o mercado passa a ser agente exclusivo e os camponeses deixam de serem sujeitos criadores de sua própria existência, pois o mercado assume essa tarefa. Imbuídos 
dessa concepção teórica muitos teóricos propõem a substituição automática do conceito de camponês pelo de agricultor familiar, excluindo as demais dimensões que constituem o modo de ser e de viver camponês, como, por exemplo, a sua apropriação do território. De acordo com Abramovay (1990)

Uma agricultura familiar, altamente integrada ao mercado, capaz de incorporar os principais avanços técnicos e de responder às políticas governamentais não pode ser nem de longe caracterizada como camponesa [...] existem assim unidades produtivas que são familiares, mas não camponesas (ABRAMOVAY, 1990, p. 7).

Essa análise privilegia a relação com o mercado e, não, as relações sociais, que não são somente econômicas. Afirmar a existência do campesinato dentro do capitalismo é considerar a possibilidade da reprodução camponesa na lógica de produção do capital dada pela constante readequação capitalista para manter as suas condições de reprodução ampliada. Como retrata Shanin (1980)

[...] sob certas condições, os camponeses não se dissolvem, nem se diferenciam em empresários capitalistas e trabalhadores assalariados e tampouco são simplesmente pauperizados. Eles persistem ao mesmo tempo em que se transformam e se vinculam gradualmente à economia capitalista circundante, que pervaga suas vidas. Os camponeses continuam a existir, correspondendo a unidades agrícolas diferentes, em estrutura e tamanho, do clássico estabelecimento rural. (SHANIN, 1980, p. 58).

Soma-se a isso o fato de que na propriedade camponesa a acumulação monetária [quando ocorre] tem por objetivo a garantia da satisfação das necessidades de consumo da família, a curto, médio e longo prazo. E isso também demonstra uma lógica avessa à capitalista, uma vez que a "acumulação de capital segue o princípio do investimento associado à expansão do trabalho assalariado" (VERGÉS, 2011, p. 83).

Sendo assim, é necessário compreender os camponeses à luz das contradições do modo capitalista de produção e do movimento constante da realidade, ou seja, a partir de sua singularidade de ser e de viver. 


\subsection{A LUTA PELA PERMANÊNCIA NA TERRA DE TRABALHO}

Os camponeses da Comunidade Ribeirão se autodenominam como pequenos produtores. São trabalhadores que adquiriram a posse da terra, em geral por herança e mantêm laços de parentesco e vizinhança que lhes permite manter a identidade camponesa, a formação comunitária e os laços de pertencimento ao lugar.

De posse da terra, as famílias camponesas desenvolvem ações que vão desde a divisão de tarefas entre os membros da família e entre as famílias da Comunidade até a ação política para ter acesso às políticas públicas. A feira camponesa, iniciativa do Movimento Camponês Popular (MCP), e a comercialização junto ao Programa Nacional de Merenda Escolar (PNAE) estão sendo experimentadas pelas famílias camponesas da Comunidade Ribeirão e, até o momento, estão sendo apontadas como um importante instrumento para assegurar a renda da e na terra (dados analisados em campo).

Diversas outras ações de caráter econômico, social, cultural e político dão sustentação ao que se pode chamar de luta pela permanência na terra e demonstram que os camponeses não aceitam a expropriação como condição predestinada e que promovem a apropriação social da natureza em oposição à apropriação privada. Esse caráter de apropriação social da natureza, mais especificamente da terra, apesar de legalmente haver a propriedade privada e individual da terra, é garantido pela existência da comunidade formada por sujeitos camponeses.

\subsection{CARACTERIZAÇÃO E LOCALIZAÇÃO DA ÁREA DA PESQUISA}

A Comunidade Ribeirão está situada no município de Catalão (GO), em sua zona rural a aproximadamente dez quilômetros da sede do município. Conta com cerca de 119 moradores segundo pesquisa publicada por Guimarães (2010). Faz divisa, ao sul, com a cidade de Catalão (GO). Limita-se ainda com as Comunidades: Coqueiros, Morro Agudo-Olaria, Tambiocó, como pode ser visto na figura (1). A principal via de acesso à comunidade é uma estrada vicinal, mas o acesso também pode ser feito pela rodovia federal BR-050 ou pela rodovia estadual GO-330, que liga Catalão $(\mathrm{GO})$ à capital do estado, Goiânia.

Na comunidade, além das propriedades rurais, há um núcleo aglutinador que conta com um centro comunitário, utilizado regularmente pela Igreja Católica para suas celebrações, e uma escola desativada, a Escola Municipal Limírio Marinho da Fonseca. 


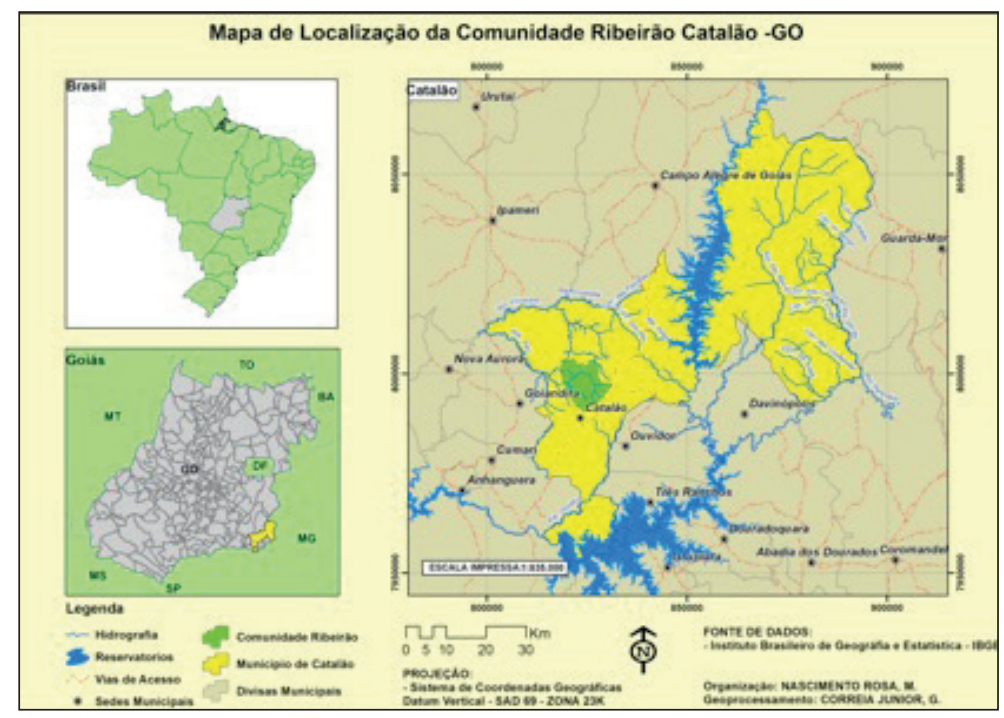

Figura 1 - Localização da Comunidade Ribeirão, no município de Catalão (GO).

Fonte: Organização: NASCIMENTO ROSA, M. (2014), Geoprocessamento: CORREIA JUNIOR, G. (2014).

\section{CONSIDERAC̣ÕES FINAIS}

A expansão do capitalismo no campo tem provocado profundas transformações nas relações sociais de produção e de trabalho presente na Comunidade Ribeirão, a ponto de suscitar interpretações que anunciaram o desaparecimento dos sujeitos que têm a terra como terra de trabalho: os camponeses. Entretanto, verifica-se que, ao contrário, os camponeses têm criado, no movimento de luta pela terra e de luta na terra, diferentes estratégias que possibilitam sua existência.

A discussão da questão agrária não pode prescindir do debate sobre a resistência camponesa na atualidade. Se, de um lado estão aqueles que usam a terra para garantir a reprodução ampliada do capital, do outro, se encontram os camponeses, cujo objetivo é a reprodução do grupo familiar. A vida camponesa não é organizada pelas necessidades do mercado, ela está assentada na forma simples de circulação de mercadoria, no processo de venda e compra, que confere à terra valor de uso. Ao contrário, a produção capitalista confere a todos os meios de produção, inclusive a terra, e aos produtos obtidos valor de troca e com vantagens, lucros, para acumulação.

O atual estágio de desenvolvimento do capitalismo, marcado por intensas mudanças desencadeadas pelo processo de mundialização do capital, traz fortes consequências para as populações camponesas. Neste contexto de avanço do agronegócio no campo, a internacionalização do capital na agricultura e a 
concentração de capitais nas mãos de grandes corporações transnacionais são desafios que tornam ainda mais difícil a compreensão de campesinato.

No caso dos camponeses que já têm a posse da terra e que nela trabalham, como os camponeses da Comunidade Ribeirão, no município de Catalão (GO), constata-se a existência de uma gama de experiências, que não significou e não significa apenas uma mudança de atividades ao longo dos anos, mas, o desenvolvimento de relações sociais de produção e de trabalho que vêm garantindo, contraditoriamente, uma relativa autonomia frente às relações capitalistas. Essas relações singulares mantêm uma lógica de ser e de viver responsável pela permanência na terra com especial atenção às condições ecológicas das áreas do Cerrado e preservação da identidade camponesa.

Assim, esse artigo que baseia-se em um projeto de pesquisa de Dissertação (em andamento) busca respostas para as seguintes questões:

a) Quais foram as configurações impostas à questão agrária a partir de 1980 com a territorialização do capital?

b) Tendo a comunidade Ribeirão no município de Catalão/Goiás como recorte espacial de análise, quais são os fatores econômicos, sociais e culturais que as famílias camponesas utilizam para permanecer na terra?

c) Como as diversas e diferentes experiências criadas e vividas pelos camponeses tornaram-se estratégias de reprodução social do campesinato?

Nesse sentido, a realidade camponesa presente na Comunidade Ribeirão é ampla e complexa, se insere em um contexto capitalista, mas preserva as condições essenciais do campesinato, portanto, o modo de vida, a economia, a cultura, a política desses camponeses é algo que requer atenção especial pelo saber geográfico. 


\section{Title: Struggle For Stay On Earth : The Peasant Livelihood Strategies In Ribeirão Community In Catalão ( Go )}

\section{Abstract}

This article refers to a reflection on the theme researched in the research project developed by the Graduate Program in Geography / UFG / Regional Catalão and results of studies and reflections made in Geography Research Group, Labour and Social Movements of the Federal University Goiás - Regional Catalan and militancy in the People's Peasant Movement (MCP). In this sense, start from the field diary, the experience with the peasant families and theoretical reflections to understand the strategies that farmers develop to stay in the land of work, from the ground- work-family triad. So understanding the strategies adopted by farmers to ensure their stay in the labor land requires the discussion of concepts that explain the historical evidence and the differential and contradictory character that peasant autonomy is the capitalist mode of production with the Community in Ribeirão municipality of Catalão / Goiás as spatial area analysis.

Keywords: Peasants; Strategies; Sojourn on Earth. 


\section{REFERÊNCIAS}

ABRAMOVAY, R. Paradigmas do Capitalismo Agrário em Questão. São Paulo: Hucitec/Edunicamp, 1992.

ALENTEJANO, P, R, R. As relacões campo-cidade no Brasil do século XXI. Ver. Terra Livre, São Paulo, v. 2, n. 21, p. 25-39, jul,/dez. 2003.

ANTUNES, R. Os Sentidos do Trabalho: ensaios sobre a afirmação e a negação do trabalho. 4 ed. São Paulo: Boitempo, 2001.

BAUMAN, Z. Comunidade: a busca por segurança no mundo atual. Tradução de Plínio Dentzien. Rio de Janeiro: Jorge Zahar, 2003.

BUBER, M. Sobre Comunidade: Selecção e tradução de M. Dascal; 0. Zimmermann. São Paulo: Perspectiva, 1987.

CARVALHO, H. M. de. 0 Campesinato Contemporâneo como Modo de Produccão e como Classe Social. Curitiba, PR, 2012. Disponivel no site: http:www.mcpbrasil.org.br. Acesso em 21 abr. 2012.

CARVALHO, H, M. de. $\mathbf{O}$ Campesinato do Século XXI - possibilidades e condicionantes do desenvolvimento do campesinato no Brasil. Petrópolis: Vozes, 2005.

CHAYANOV, A. V. La Organización de la Unidad Económica Campesina. Tradução Rosa María Russovich. Buenos Aires: Nueva Visión, 1974.

CHESNAIS, F. A Mundialização do Capital. São Paulo: Xamãa, 1996.

CONCEIÇÃO, A. L. A Questão Camponesa: 0 Olhar sob o Signo Dialético. Dissertação de Mestrado. Núcleo de Pós-Graduaç̃õo em Geografia - NPGEO/UFS, Aracaju, 1991.

FABRINI, J, E. A Contradição Como Parâmetro de Compreensão da Existência Camponesa. Revista Geografia, vol. 13, n. 2, jul-dez, 2004.

FERNANDES, B, M. Agricultura Camponesa e/ou Agricultura Familiar. Córdoba-Argentina, p 1-9, 2008. Disponivel em: <HTTP//WWW.capacitacionapn.com.ar/cfycap/.../agricultura camponesa.pdfs. Acesso em: FERNANDES, B, M. Entrando nos territórios do território. In: PAULINO, E. T; FABRINI, J. E. Campesinato e território em disputa. São Paulo: Expressão Popular, 2008. p. 212-239.

GALEANO, E. H. As Veias Abertas da América Latina. 22 ed. Rio de Janeiro: Paz e Terra, 1986.

GRAZIANO DA SILVA, J. A Modernização Dolorosa: estrutura agrária, fronteira agrícola e trabalhadores rurais. Rio de Janeiro: Zahar, 1982.

GRZYBOWSKI, C. Caminhos e Descaminhos dos Movimentos Sociais no Campo. 2. Ed. Petrópolis: Vozes, 1990.

HAESBART, R. 0 Mito da Desterritorialização: do "fim dos territórios" à multiterritorialidade. 4 ed. Rio de Janeiro: Bertrand Brasil, 2009.

HARVEY, D. A Produção Capitalista do Espaço. São Paulo, Annablume, 2005.

HARVEY, D. Condição Pós-Moderno. Uma pesquisa sobre as Origens da Mudança Cultural. Edições Loyola, 2008.

IBGE. Instituto Brasileiro de Geografia e Estatística. Disponível em < http://www.ibge.gov.br/home/default.php. Acesso em 2013. 
KAUTSKY, K. A Questão Agrária. 3. Ed. São Paulo: Proposta, 1980.

LUNA, S. V. de. Planejamento de Pesquisa: uma introdução. 8 ed. São Paulo: EDUC, 2005.

LUXENBURGO, R. A Acumulação do Capital. Tradução de José Paulo Netto. São Paulo: Nova Cultura, 1985.

MARTINS, J, S. A Chegada do Estranho. São Paulo: Hucitec, 1993.

MARTINS, J, S. Expropriação \& Violência. A questão política no campo. São Paulo: Hucitec, 1991.

MARTINS, J, S. 0 Cativeiro da Terra. São Paulo: Ciências Humanas, 1979.

MARTINS, J, S. Os Camponeses e a Política no Brasil. $5^{\circ}$ ed. Petrópolis (RJ): Vozes, 1981.

MARX, K. 0 Capital. Crítica da Economia Política: Livro l: o processo de produção do capital / Karl Marx; [ tradução de Rubens Enderle]. - São Paulo: Boitempo, 2013.

MENDONÇ, M, R. A Questão Regional e o Campesinato: a alhicultura em Catalão-G0. 1998. $233 f$. Dissertação (Mestrado em História das Sociedades Agrárias) - Instituto de Ciências Humanas e Letras, Universidade Federal de Goiás, Goiânia.

MESQUITA, H, A. de A Modernização da Agricultura: um caso em Catalão-Goiás. 1993, 180f. Dissertação (Mestrado em História das Sociedades Agrárias), Universidade Federal de Goiás, Instituto de Ciências Humanas e Letras, Goiânia, 1993.

MÉSZÁROS, I. Para Além do Capital. São Paulo: Boitempo editorial, 2002.

MOREIRA, R. Pensar e Ser em Geografia. São Paulo: Contexto, 2007.

NASCIMENTO, A. C. \& MENDONC,A, M. R. Campesinato: uma existência contraditória no modo capitalista de produção. Anais Cemarx, Campinas, SP, 2012.

OLIVEIRA, A, U. A Geografia das Lutas no Campo. São Paulo: Contexto, 1999.

OLIVEIRA, A, U. Agricultura Camponesa no Brasil. São Paulo: Contexto, 2001.

OLIVEIRA, A, U. Modo Capitalista de Produção, Agricultura e Reforma Agrária. São Paulo: FFLCH/ Labur, ediç̃ões, 2007.

OLIVEIRA, A. U. de.; MARQUES, M. I. M. (Orgs). 0 Campo no Século XXI: território de Vida, de Luta e de Construção da Justiça Social. São Paulo. Editora Casa Amarela e Editora Paz e Terra, 2004.

PAULINO, E, T. Por uma Geografia dos Camponeses. São Paulo, editora Unesp, 2006.

PRADO JÚNIOR, C. A Questão Agrária no Brasil. 5 ed. São Paulo: Brasiliense, 2000.

PORTO GONCALVES, C, W. A Globalização da Natureza e a Natureza da Globalização. Rio de Janeiro, Civilização Brasileira, 2006.

SANTOS, M. Técnica, Espaço e Tempo: globalização e meio técnico-ciêntifico informacional. São Paulo: Hucitec, 1994.

SHANIN, T. A Definição de Camponês: Conceituações e Desconceituações - o velho e o novo em uma discussão marxista. Estudos Cebrap, Petrópolis, n. 26, pp. 43-79, 1980.

SHANIM, T. Lições Camponesas. In: PAULINO, E, T. FABRINI, J, E. Campesinato e Territótio em Disputa. São Paulo: Expressão Popular, 2008.

SMITH, N. Desenvolvimento Desigual. Tradução de Eduardo de Almeida Navarro. Rio de Janeiro: Bertrand Brasil, 1988.

THOMAZ JÚNIOR, A. As Correntes Teóricas na Geografia Agrária Brasileira. Presidente Prudente, SP, 2009. 
VERGÉS, A. B. Os Novos Camponeses. São Paulo: Cultura Acadêmica; Cátedra Unesco de Educação do Campo e Desenvolvimento Rural, 2011.

VENÂNCIO, M; PESSOA, V. L. S. 0 diário de campo e a construção da pesquisa: registro das emoç̃oes dos sujeitos envolvidos e a reconstrução de suas histórias de vida e do lugar. In: RAMIRES, J. C. de L.; PESSOA, V. L. S. (Orgs.) Pesquisa Qualitativa: nas trilhas da investigaccão. Braślia/Rio de Janeiro: Editora UnB/Tempo Brasileiro, 1990. 